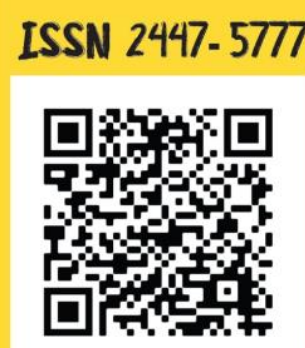

Jan. | Jun. 2021 - Volume 7, Número 1, p. 1-21.

\title{
Os estudos de Thomas Young sobre a acomodação ocular: análise do episódio e tradução comentada do texto “Observations on vision” (1793)
}

\author{
Thomas Young's studies on visual accommodation: an analysis of the episode \\ and a commented Portuguese translation of his "Observations on vision"(1793)
}

Jean Batista Apolinário Costa ${ }^{1}$ - https://orcid.org/0000-0002-9104-4863
Breno Arsioli Moura ${ }^{2}$ - https://orcid.org/0000-0003-2130-7055

${ }^{1}$ Graduando em Ciência e Tecnologia, Universidade Federal do ABC (UFABC), Santo André, SP, Brasil. Email: jean.costa@aluno.ufabc.edu.br

${ }^{2}$ Doutor em Ensino de Ciências, Universidade de São Paulo (USP). Professor da Universidade Federal do ABC (UFABC), Santo André, SP, Brasil. E-mail: breno.moura@ufabc.edu.br

\begin{abstract}
Resumo
Neste artigo, apresentamos uma tradução comentada para o português do texto "Observations on vision" (1793), de Thomas Young (1773-1829), seu primeiro trabalho publicado nas Philosophical Transactions da Royal Society. Nesse texto, Young discutiu algumas teorias e ideias sobre a acomodação visual existentes até sua época. Após apontar diversas falhas nessas teorias, ele propôs a sua, baseada na existência de uma musculatura no cristalino responsável especificamente por esse mecanismo. A tradução é precedida por três seções, em que aspectos da história da anatomia ocular e das teorias anteriores para a acomodação visual são abordados, a fim de contextualizar a leitura do material traduzido.
\end{abstract}

Palavras-chave: Acomodação visual. Óptica. Visão. Thomas Young. Luz.

\begin{abstract}
In this paper, we present a commented Portuguese translation of Thomas Young's (1773-1829) "Observations on vision" (1793), his first published paper in Royal Society's Philosophical Transactions. In this article, Young discussed some previous theories and ideas on visual accommodation up to his days. After pointing out the flaws of these theories, he proposed his own: muscles in the crystalline lens were responsible for this mechanism. The translation is preceded by three sections in which we comment on aspects of the history of eye anatomy and of the previous theories for visual accommodation, in order to contextualize the reading of the translated material.
\end{abstract}

Keywords: Visual accommodation. Optics. Vision. Thomas Young. Light.

Como citar: COSTA, J. B. A.; MOURA, B. A. Os estudos de Thomas Young sobre a acomodação ocular: análise do episódio e tradução comentada do texto "Observations on vision" (1793). Ensino \& Multidisciplinaridade, v. 7, n. 1, p. 1-21, 2021. 


\section{Introdução}

O filósofo natural inglês Thomas Young (1773-1829) apresentou contribuições em diversas áreas do conhecimento, desde a óptica até a egiptologia. $\mathrm{Na}$ história da óptica, seus estudos sobre o fenômeno de interferência luminosa são frequentemente associados à ascensão da concepção ondulatória da luz no século 19, e na cultura popular ele é lembrado como formulador do experimento da fenda dupla. Mas Young não se destacou apenas nisso. Formouse médico, estudando entre 1794 e 1800 nas universidades de Edimburgo, Göttingen e Cambridge, e, posteriormente, estabeleceu-se em Londres. A medicina influenciou profundamente a direção de seus estudos na filosofia natural, pois, segundo ele, foi seu interesse na visão e na audição que o levou a pesquisar a fundo sobre a luz e som (YOUNG, 1978, p. 253).

A primeira publicação de Young nas prestigiadas Philosophical Transactions da Royal Society foi intitulada "Observations on vision" (YOUNG, 1793) e abordou o processo fisiológico conhecido como acomodação visual. Durante a acomodação, os raios luminosos incidentes no olho são trazidos ao foco na retina, permitindo a observação de objetos em distâncias variáveis. Não era conhecida com exatidão a maneira pela qual esse fenômeno ocorria, e muitos voltaram sua atenção ao problema durante os séculos 17 e 18. Nesse texto, Young buscou explicar a acomodação, fazendo o uso de saberes de anatomia, matemática e óptica geométrica. Esse primeiro escrito óptico representou o estágio inicial de seu envolvimento com a ciência da visão.

No presente artigo, trazemos uma análise desses estudos iniciais de Young sobre a visão, bem como apresentamos, ao final, uma tradução para o português do "Observations on vision". Essa análise buscará mostrar, por um lado, quais eram os conhecimentos sobre visão e anatomia ocular na época de Young e, por outro, como ele buscou aprimorá-los. A pertinência de uma análise como essa e da tradução do texto de Young se revela pela pouca disponibilidade de artigos em português sobre o autor britânico. Até o momento, apenas um de seus artigos possui tradução completa para o português (MOURA; BOSS, 2015) e raros são os estudos sobre outros aspectos de sua óptica que não a interferência luminosa e o experimento da fenda dupla (OLIVEIRA et al., 2019). No contexto de ensino de ciências, o acesso ao material original de Young pode suscitar debates sobre sua incursão inicial na filosofia natural, seus métodos de pesquisa, o modo como criticou as ideias de filósofos anteriores, entre outros pontos.

Nas páginas a seguir, consideramos inicialmente os aspectos da anatomia ocular conhecidos no século 18. Em seguida, discutimos as explicações para a acomodação visual e as principais teorias que influenciaram Young. Um panorama do conteúdo do "Observations on vision" é fornecido na seção posterior, com a tradução para o português encerrando este artigo.

\section{Estudos sobre anatomia ocular até o século 18}

Desde a antiguidade clássica, filósofos e anatomistas buscaram compreender o funcionamento da visão humana. Na Grécia, pensadores como Herófilo (325-255 a.C.) e Erasístrato (304-250 a.C.) estudaram a anatomia ocular detalhadamente, e diversas escolas filosóficas propuseram explicações qualitativas sobre a percepção visual, as quais deram origem a várias tradições divergentes. Inicialmente, essas explicações acerca da visão não integravam aspectos anatômicos. O primeiro pensador a realizar essa síntese foi Galeno (c.130c.210), que buscou explicar a função dos componentes oculares na percepção visual (SMITH, 2015, p. 36-43). A influência galênica posteriormente se fez presente nas descrições anatômicas do mundo islâmico medieval, onde trabalhos clássicos influenciaram e incentivaram novos estudos ópticos. No século 12, a tradução desse corpus grego e islâmico ao latim permitiu aos 
europeus o acesso a diversas teorias ópticas e descrições anatômicas, as quais foram gradualmente assimiladas, discutidas e adaptadas nas universidades então recentemente criadas (LINDBERG, 1976; 2008). Contudo, existia discordância na literatura médica acerca de aspectos gerais da estrutura ocular. ${ }^{1}$

Anatomistas renascentistas como Leonardo da Vinci (1452-1519), Andreas Vesalius (1514-1564) e Felix Platter (1536-1614) descreveram a anatomia humana de maneira mais precisa que seus antecessores, possibilitando novos avanços na compreensão da visão. Seus trabalhos contrapunham algumas noções equivocadas presentes na literatura médica acerca do olho, corrigindo, por exemplo, a posição exata do humor cristalino ${ }^{2}$ e do nervo óptico ${ }^{3}$ (SMITH, 2015, p. 351-352). Em especial, Platter deixou explícito que o humor cristalino não era responsável pela percepção visual, como assumiam teorias anteriores, mas sim uma lente que focava os raios luminosos na retina. Fundamentando-se nessas novas descrições e em sua própria teoria óptica, Johannes Kepler (1571-1630) afirmou que essa imagem formada na retina deveria ser real e invertida, de modo similar a uma camera obscura. No decorrer do século 17 , consolidou-se o papel da retina como local de formação da imagem (OSBORNE, 1979, p. 3962). Como resultado, não havia mais um paradigma favorável às teorias de extramissão visual, prevalecendo o entendimento do olho como agente passivo, e não ativo, no recebimento dos raios luminosos (SMITH, 2015, p. 352). O diagrama de René Descartes (1596-1650), publicado na metade do século 17, é um exemplo da maneira que os anatomistas do período representavam o sistema visual (Figura 1).

Essas considerações teóricas e anatômicas definiram o rumo a ser seguido pelo estudo da anatomia ocular no século seguinte. No século 18, era conhecido que o olho funcionava como um sistema óptico, de modo que o percurso da luz incidente obedecia às leis da óptica geométrica. Os raios luminosos eram refratados pelos componentes oculares, passando através da lente cristalina antes de atingir o foco na retina. Também ocorriam refrações na córnea e nas substâncias líquidas que preenchiam o interior ocular, os humores aquoso e vítreo (SMITH, 1738, p. 25-32). Os raios luminosos finalizavam seu percurso ao atingir a retina, e a informação visual era subsequentemente transmitida ao cérebro por meio do nervo óptico. ${ }^{4}$

\footnotetext{
${ }^{1} \mathrm{Na}$ literatura anatômica islâmica do século 9, por exemplo, existia uma grande discordância quanto ao número de camadas oculares. Como descreveu o médico e tradutor Hunain ibn Ishaq (808-873), dependendo da fonte, a quantidade de camadas variava entre sete e duas (LINDBERG, 1976, p. 34-41).

${ }^{2}$ Atualmente conhecido como "cristalino" ou "lente do olho". Durante o período medieval, esse componente ocular era usualmente denominado "humor cristalino", como fora chamado por Galeno (LINDBERG, 1976; SMITH, 2015, p. 39). Após anatomistas tomarem conhecimento de que essa estrutura funcionava como lente, passou a ser comum chamá-la de "lente cristalina". No tempo em que Young escreveu seus trabalhos sobre acomodação visual, de maneira geral, todos esses termos eram utilizados para se referir ao mesmo componente ocular. Neste parágrafo, utilizamos o termo "humor cristalino" para evitar anacronismo.

${ }^{3}$ Durante a Idade Média, era comum descrever o cristalino como localizado no centro exato do olho, ao invés de sua posição correta, próximo à córnea. Historiadores da ciência inicialmente atribuíram esse erro a Galeno, mas estudos recentes argumentam que esse provavelmente originou-se na Arábia medieval (LEFFLER et al., 2016). O nervo óptico, por sua vez, era descrito como alinhado ao eixo ocular, o que também é incorreto.

${ }^{4}$ Os processos fotoquímicos que ocorrem na retina ainda não haviam sido descritos no século 18. Existiam teorias sobre a transmissão da imagem pelo nervo óptico e sobre a percepção de cores, mas a descrição precisa de ambos os processos foi um desenvolvimento posterior.
} 


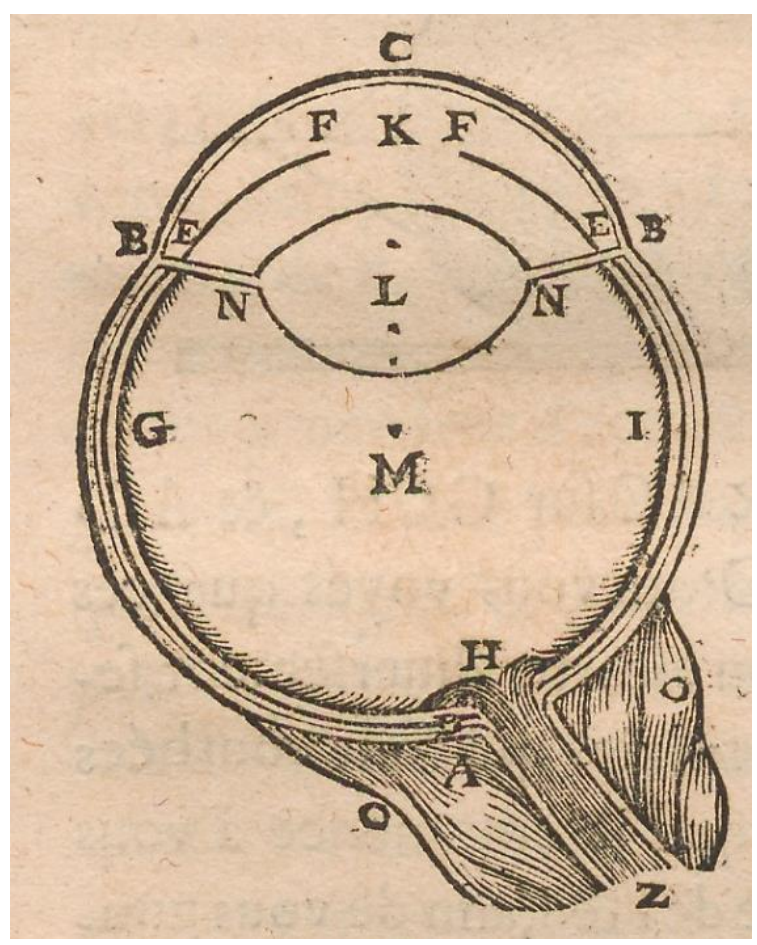

Figura 1 - Diagrama de René Descartes (1596-1650), publicado em seu Dióptrica (1658). Nele, é apresentada uma seção transversal do órgão da visão, ilustrando os aspectos básicos da anatomia ocular. Entre outros componentes, estão representados a córnea $(\mathrm{C})$, íris (EF, EF) pupila $(\mathrm{FF})$, humor aquoso $(\mathrm{K})$, lente cristalina $(\mathrm{L})$, processos ciliares $(\mathrm{EN}, \mathrm{EN})$ humor vítreo $(\mathrm{M})$, retina $(\mathrm{GH}, \mathrm{HI})$, e o nervo óptico $(\mathrm{HZ})$. A luz incide pela córnea, passando pelo humor aquoso, lente cristalina, humor vítreo e finalizando seu percurso ao encontrar a retina, onde a imagem é projetada. Comparando a representação de Descartes com o diagrama de Thomas Young (Figuras 3 e 4, a seguir), vemos que não houve mudanças significativas nos aspectos gerais da anatomia ocular, bem como sua terminologia, os quais já eram bem estabelecidos.

Fonte: Descartes (1658, p.16).

Estudantes britânicos de medicina encontravam facilmente descrições detalhadas da estrutura ocular em livros de anatomia geral ou livros especializados sobre o órgão da visão. Eles possuíam à sua disposição tanto autores conterrâneos quanto autores da Europa continental. Mesmo com os conflitos intermitentes entre a Inglaterra e a França, trabalhos de anatomistas franceses encontravam espaço nas prateleiras britânicas, como An anatomical exposition of the structure of the human body (1733) de Jacques-Bénigne Winslow (16691760), acessível em latim e inglês. Além disso, existia uma grande movimentação de estudantes de medicina para as universidades de Göttingen e Leiden, certamente facilitando o acesso a trabalhos de autores germânicos como Johann Gottfried Zinn (1727-1759). Para o público nãoespecializado, existiam publicações como as de Benjamin Martin (1705-1782), contendo descrições da anatomia ocular de maneira não aprofundada. Artigos acerca do funcionamento do olho e da percepção visual encontravam espaço em periódicos como as Philosophical Transactions da Royal Society de Londres, e, como parte da óptica, também atraíam a atenção de filósofos naturais.

\section{Fisiologia ocular: acomodação}


Enquanto a anatomia examina aspectos estruturais de um órgão, a fisiologia estuda seu funcionamento. Conforme apontamos na seção anterior, ao longo do século 18, médicos britânicos em exercício e em formação dispunham de descrições anatômicas geralmente precisas e um bom entendimento do papel do cristalino e da retina no recebimento dos raios luminosos. Além disso, dentre todos os sentidos externos, o sentido da visão era o mais bem compreendido (YOUNG, 1801, p. 25). Contudo, alguns detalhes da fisiologia ocular permaneciam sem uma explicação unificada, dando origem a abundantes explicações divergentes.

No século anterior, anatomistas e filósofos naturais haviam voltado sua atenção para a questão fisiológica do foco visual. Era conhecido que, ao posicionar em seu campo de visão dois objetos, um distante e outro próximo, o olho era capaz de alterar seu foco para observar com clareza os dois alternadamente. ${ }^{5}$ Isso não seria possível sem a ocorrência de uma alteração física do olho. Dessa maneira, algum processo em seu interior deveria ser responsável por alterar o foco dos raios de luz na retina, tornando possível observar objetos a distâncias variáveis. O processo foi nomeado de acomodação visual. Mas, qual processo exatamente seria esse?

Pode-se distinguir dois elementos necessários para propor uma teoria que explique a acomodação. Em primeiro lugar, era preciso identificar alguma alteração material nos componentes do olho. Essa alteração seria responsável por modificar o local onde os raios luminosos eram coletados na retina, explicando assim o ajuste de foco na visão. Em segundo lugar, era evidente que tal alteração não ocorreria sem algum agente, portanto, era necessário identificar e verificar qual agente anatômico efetuaria essa alteração. Nas teorias propostas, esse agente era sempre associado a contrações musculares. O principal candidato para músculo acomodativo era a estrutura chamada "processos ciliares", composta por diversos filamentos arranjados de maneira circular. Essa estrutura se encontra em um local conveniente para as teorias de acomodação, já que é a extensão de uma camada ocular, e está conectada aos ligamentos suspensórios que mantêm a lente cristalina no lugar. A existência de um músculo agindo na região ciliar havia sido suspeita desde o século 16, e grande parte das teorias de acomodação fizeram uso dessa suposta musculatura para explicar o processo acomodativo (HARPER, 2014). Existiam também outras possibilidades a serem exploradas, como a musculatura da própria lente.

Longe de existir um consenso, esses elementos variavam frequentemente de autor para autor (OSBORNE, 1979). Tanto a alteração quanto o mecanismo poderiam ocorrer de maneiras diversas, de modo que diferentes combinações resultariam, teoricamente, no mesmo ajuste de foco. Isso explica a quantidade de teorias divergentes propostas no período, algumas das quais eram completamente incompatíveis entre si. Algumas teorias acomodativas, por exemplo, afirmavam que a acomodação diminuía a distância focal do olho, enquanto outras propunham seu aumento. Era então necessário demonstrar, de alguma maneira, qual dessas possibilidades ocorria de fato no interior ocular.

\footnotetext{
${ }^{5}$ Como descrito por Descartes: "E vós podeis conhecer esse movimento pela experiência, pois se, quando olhardes fixamente uma torre ou uma montanha um pouco distante, apresentarmos um livro diante de vossos olhos, vós não podereis aí ver nitidamente nenhuma letra até que sua figura seja um pouco mudada." (DESCARTES, 2010, p. 466).
} 


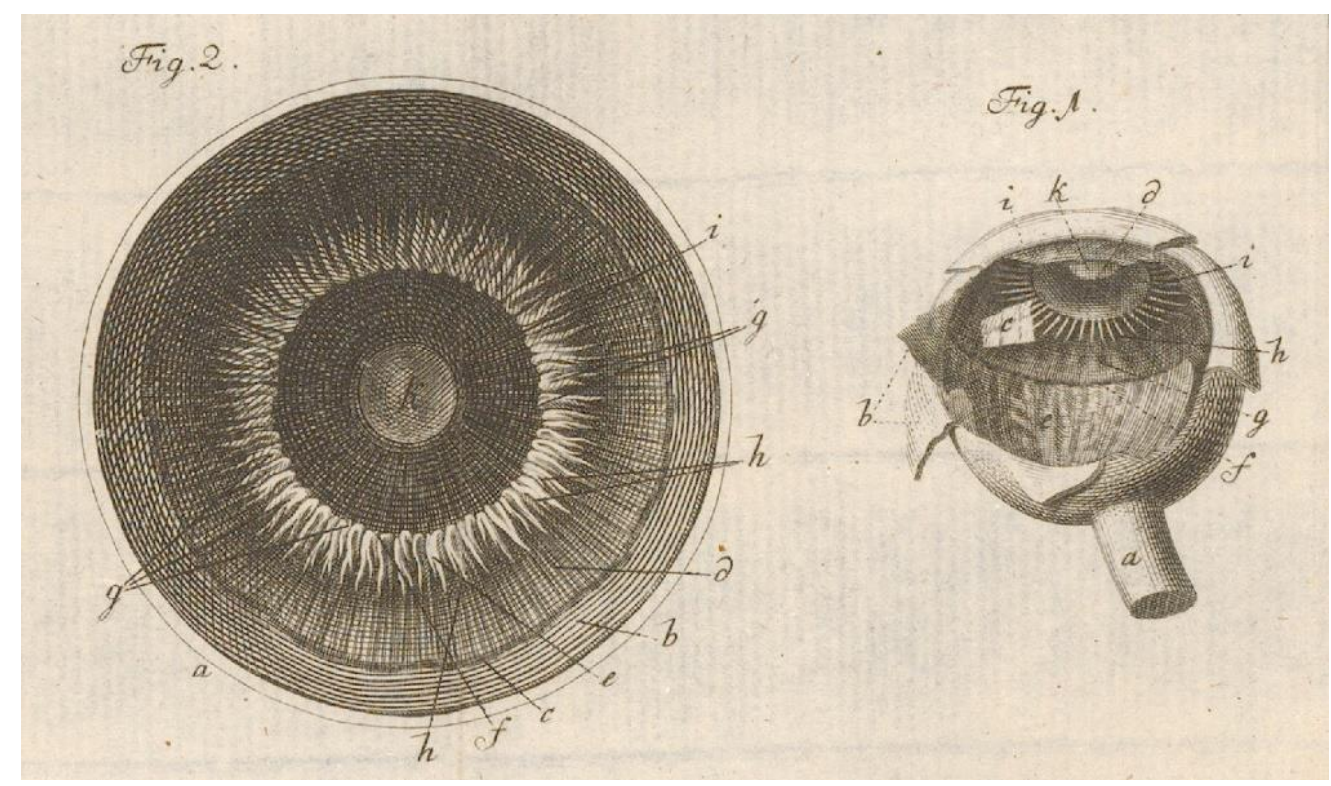

Figura 2 - Na ilustração à esquerda, vemos uma seção transversal do corpo ciliar: (a,b) são as camadas oculares esclerótica e coroide; (e,f,g,h) são partes do corpo ciliar; (k, no centro) a pupila. Na ilustração à direita está representado um olho com suas camadas exteriores abertas. Podemos observar (k) a pupila; (d) lente cristalina; (c) humor vítreo; (g,h) processos ciliares; (a) nervo óptico. Imagem disponível em Descriptio anatomica oculi humani iconibus illustrata (1755), por Johann Gottfried Zinn.

Fonte: Zinn (1755, Tab. II).

Um grande obstáculo em determinar experimentalmente o mecanismo acomodativo era a impossibilidade de observar diretamente quais alterações internas ocorriam durante o processo. Por considerações práticas e éticas, não era viável dissecar olhos de animais vivos (BATES, 2014), portanto o órgão da visão deveria ser observado em seu estado morto e estático, sendo inferido daí seu funcionamento em vida. Alternativamente, era possível observar a parte exterior de um olho vivo, mas sem obter informações sobre seu interior. Além disso, as dissecções nem sempre resultavam em informações precisas, visto que os componentes oculares internos estavam sujeitos a sofrer alterações após a morte do animal, de modo a não corresponder exatamente ao seu estado em vida (OSBORNE, 1979, p. 16-22). A densidade da lente, por exemplo, é reduzida após a morte, o que altera seu índice refrativo (YOUNG, 1801, p. 42). Outros fatores que influenciavam a acurácia das descrições eram a habilidade do anatomista e os instrumentos disponíveis na época.

No caso dos anatomistas e filósofos naturais britânicos ao final do século 18, havia também uma dificuldade em obter cristalinos humanos para observação. A disponibilidade de corpos humanos para dissecção nas escolas de anatomia era severamente limitada pela lei vigente à época, que permitia apenas a dissecção de criminosos executados por enforcamento (BURROWS, 2019, p. 29). Com o número de estudantes médicos em ascensão e o de execuções em baixa, a demanda de corpos não era suprida legalmente. Para o estudo da acomodação, uma solução era realizar a dissecção de olhos animais, como o de boi, partindo do pressuposto de que o mecanismo acomodativo seria similar ao do olho humano. Dessa forma, também deveria ser levado em consideração a maneira com que esses diferiam, levantando questões sobre a validade das inferências realizadas. Hoje sabe-se que o processo acomodativo, na realidade, pode variar entre as espécies, e que a maioria das possibilidades exploradas no período, de fato, ocorre no reino animal (GLASSER, HOWLAND, 1996; OTT, 2006). 
Um exemplo de conclusão errônea foi uma asserção de Antonie van Leeuwenhoek (1632-1723), o qual, em 1704, havia observado fibras no cristalino. A partir dessa observação, ele concluiu que a própria lente deveria ser um músculo. Essas fibras, contudo, não eram de fato musculares (de JONG, 2020, p. 99). Em contraste, William Porterfield (1696-1771) observou corretamente que pacientes cuja lente cristalina fora removida durante a cirurgia de catarata perdiam seu poder de acomodação, algo que sugeria fortemente o protagonismo do cristalino no processo acomodativo.

De maneira geral, a experimentação direta pouco contribuiu para o estudo da acomodação nos séculos 17 e 18, enquanto considerações especulativas tiveram papel fundamental (OSBORNE, 1979). Por exemplo, teorias acomodativas comumente pressupunham a musculatura dos processos ciliares, apesar de não existir demonstração de tal fato. Algumas teorias supunham a musculatura de outros componentes oculares, como a da própria lente, já outras optavam por mecanismos alternativos, como alterações na íris e na córnea. Uma das consequências disso foi a falta de uma explicação unificada para o fenômeno até o meio do século 19.

\section{O “Observations on vision” (1793) de Thomas Young}

Thomas Young iniciou seus estudos médicos em 1792, com o apoio de seu tio-avô Richard Brocklesby (1722-1797), reconhecido médico londrino. No período, o ensino de anatomia era uma das principais fontes de renda para os anatomistas britânicos, existindo, portanto, uma variedade de escolas privadas no ramo (MITCHELL et al., 2011). Uma dessas escolas era a Hunterian School, de Londres, fundada por William Hunter (1718-1783) e seu irmão, John Hunter (1728-1793). Young inscreveu-se na Hunterian School em 1792, e no ano seguinte inscreveu-se também no hospital de St. Bartholomew. Dessa maneira, rodeado por praticantes médicos, hospitais e bibliotecas, Young teve à sua disposição vários trabalhos anatômicos. Sabe-se que leu textos de importantes anatomistas do período, como Winslow, Bernhard Siegfried Albinus (1697-1770) e Albrecht Haller (1708-1777). Como resultado de seus estudos sobre a anatomia ocular, interessou-se pelo funcionamento do processo acomodativo e gradualmente familiarizou-se com as teorias de acomodação.

Levando em consideração a observação de Porterfield acerca da remoção do cristalino em cirurgias de catarata, além de outras considerações anatômicas, Young suspeitou que a acomodação fosse resultado de uma musculatura da cápsula do cristalino. Contudo, descartou essa ideia após realizar suas próprias dissecções oculares em um olho de boi - ao que tudo indica, recentemente abatido - e analisar o cristalino sob uma luz forte. Com a ajuda de uma lupa, ele observou diversas fibras ao longo da lente, o arranjo das quais, segundo ele, era indício da existência de musculatura no próprio cristalino. Essa já havia sido proposta anteriormente, mas Young afirmou que não estava ciente disso quando realizou tal observação. ${ }^{6}$ Em algum momento antes de maio de 1793, inteirou-se de outras teorias acomodativas e do trabalho de Leeuwenhoek, onde o mesmo descreveu a lente como sendo um músculo.

A partir desses estudos, Young concluiu que a lente cristalina era uma estrutura muscular, cuja contração, segundo ele, teria como consequência necessária um aumento na convexidade da lente como um todo. Consequentemente, reconheceu também que o olho trazia ao foco objetos longínquos quando estava em estado de repouso, e que o processo de acomodação consistia na redução dessa distância focal. Ele propôs sua própria teoria acomodativa: quando a mente manifestasse a vontade de observar um objeto próximo, essa

\footnotetext{
${ }^{6}$ Caso tal afirmação feita em "Observations on Vision" seja verdadeira, Young deve ter realizado suas dissecções iniciais antes de aprender sobre a teoria de Henry Pemberton (1694-1771) e as observações de Leeuwenhoek.
} 
vontade seria transmitida até as fibras da lente, as quais se contrairiam de modo a tornar o cristalino mais esférico. Essa mudança de convexidade teria como consequência o efeito desejado, uma alteração no foco da imagem na retina.

De acordo com Young, sua teoria se aplicaria a quadrúpedes e era incapaz de explicar a acomodação em peixes. Como o cristalino de peixes era naturalmente esférico, tal alteração de forma não poderia ocorrer. Como evidenciado por sua breve comunicação na Gentleman's Magazine (YOUNG, 1792), publicada aproximadamente no mesmo período, Young acreditava na validade da regra filosófica proposta no Principia de Newton de que efeitos iguais deveriam, em geral, possuir causas iguais. ${ }^{7}$ A suposição de que os processos acomodativos em diferentes espécies deveriam funcionar de maneira similar era um dos fatores que permitia generalizar os achados nos olhos de quadrúpedes aos olhos humanos, mas também garantia que a limitação apresentada pelos olhos de peixe fosse relevante, apesar de não comprometer seriamente a teoria.

Essa teoria acomodativa foi apresentada em seu artigo "Observations on vision" (YOUNG, 1793), provavelmente escrito nos meses entre setembro de 1792 e maio de 1793. Esse artigo foi a primeira publicação de Young relacionada à óptica, aos dezenove anos de idade, e seu primeiro texto nas Philosophical Transactions da Royal Society. Ele iniciou o artigo enumerando e rejeitando algumas teorias anteriores, as quais considerava incorretas ou incompletas, adotando o mesmo modelo argumentativo utilizado por Porterfield e James Jurin (1684-1750) em seus trabalhos sobre a acomodação. Em seguida, descreveu suas observações com o cristalino de boi, apresentou sua teoria acomodativa, e buscou demonstrar que a alteração de forma proposta por ele resultaria no efeito desejado. Ao final do artigo, procurou responder a algumas questões ópticas relacionadas à visão e fisiologia visual. De maneira geral, seu estilo de escrita foi formal e utilizou termos médicos em abundância. Nos trechos onde empregou a matemática e a óptica, contudo, Young apresentou apenas as proposições utilizadas e o resultado obtido, sem expandir o raciocínio. Provavelmente, considerou que seu público-alvo estava familiarizado com os termos e procedimentos descritos. ${ }^{8}$

Nota-se que Young buscou evitar o uso de hipóteses ao formular sua teoria acomodativa. A musculatura do cristalino foi proposta com base em dados empíricos, visto que afirmou ter observado fibras na lente cujo arranjo, segundo ele, indicava a presença de uma musculatura. A alteração de forma do cristalino, por sua vez, foi baseada na disposição dessas fibras, e em seguida justificada matematicamente por meio de um corolário de cálculo fluxional. Nos trechos seguintes, para verificar se tal alteração seria suficiente para explicar a acomodação, utilizou a óptica geométrica para calcular numericamente o novo local de foco. Enquanto grande parte das teorias anteriores trataram o problema apenas de maneira qualitativa, Young buscou aplicar seu conhecimento de filosofia natural e matemática, verificando numericamente afirmações de difícil confirmação experimental. Essa síntese entre a filosofia natural e fisiologia também se fez presente em seus artigos posteriores.

Nesse momento de seus estudos, a discussão de Young sobre a visão ainda não abrangia a questão da natureza da luz, e, como estudante de medicina, seu foco era em aspectos anatômicos. Por conseguinte, absteve-se de comentar sobre essa questão, fazendo uso do fato de que, para a finalidade de seu artigo, o aspecto físico do fenômeno da refração, assim como as propriedades das lentes, independia de uma interpretação sobre a luz, fosse ela um

\footnotetext{
${ }^{7}$ Young fez referência à segunda regra de raciocínio em filosofia, descrita em Newton (2008, p. 185).

${ }^{8}$ Segundo seu biógrafo, George Peacock (1791-1858), o fato de Young ter recebido sua educação de maneira relativamente isolada às outras pessoas de sua idade pode ter resultado em uma falta de consciência sobre o conhecimento dos outros (PEACOCK, 1855, p. 29-30). Young pareceu assumir, por exemplo, que seu leitor possuía um bom domínio dos temas discutidos e entendimento da matemática e da óptica utilizada.
} 
corpúsculo, um pulso, uma onda ou um fluido. ${ }^{9}$ Contudo, Young já havia lido o Óptica (1704) de Newton nos anos anteriores, e seu leque de citações conteve autores que favoreciam uma concepção corpuscular da luz, como Pieter van Musschenbroek (1692-1761) e Robert Smith (1689-1768). Portanto, é natural supor que, em 1793, ele já estava ciente do predomínio dessa concepção nas obras sobre a luz do período. Ademais, a presença da seção de questões ópticas, assim como seu uso da óptica geométrica, indicam uma avançada compreensão do tema. Young certamente já possuía uma boa base na óptica e na matemática para fundamentar seus estudos futuros.

Pouco após a publicação desse artigo, Young foi eleito membro da Royal Society. Nos anos seguintes, prosseguiu para estudar medicina nas universidades de Edimburgo, Göttingen e Cambridge, e então procurou estabelecer sua prática médica em Londres. Nesse meio tempo, novas publicações sobre a acomodação haviam surgido, como a de Everard Home (1756-1832) com o auxílio de Jesse Ramsden (1735-1800), nas quais a observação de Porterfield sobre a remoção do cristalino foi contestada, e um artigo de David Hosack (1769-1835), que questionou a conclusão de Young sobre a musculatura do cristalino (HOME, 1794; HOSACK, 1794). Além disso, nova atenção foi direcionada ao estudo das cores e da percepção visual após o filósofo natural John Dalton (1766-1844) publicar um artigo descrevendo sua visão anormal, hoje conhecida em português como daltonismo (DALTON, 1798; MUSSELMAN, 2006, p. 55-72).

Em 1801, Young retornou à acomodação em sua Bakerian Lecture "On the mechanism of the eye" (1801), dessa vez conseguindo formular e realizar uma série de experimentos de maneira a provar que a alteração ocorria de fato no cristalino - uma grande inovação, considerando a falta de experimentação nas teorias anteriores -, reafirmando a observação de Porterfield. A musculatura do cristalino, contudo, já não era tão certa. No ano seguinte, em "Sobre a teoria de luz e cores" (MOURA; BOSS, 2015), investigou a percepção de cores e propôs sua teoria tricromática, na qual o olho possuía três tipos de receptores de cores. As contribuições de Young na óptica fisiológica foram de grande importância para o entendimento da visão.

\section{Tradução $^{10}$}

[p. 169] XVI. Observações sobre a Visão. Por Thomas Young. Comunicadas por Richard Brocklesby, M.D. F.R.S.

\section{Lido em 30 de maio, 1793.}

É bem conhecido que o olho, quando não está sob a ação de qualquer esforço da mente, comunica uma impressão distinta ${ }^{11}$ apenas daqueles objetos que estão situados a uma certa distância dele; que essa distância é diferente em pessoas diferentes, e que o olho pode, pela volição ${ }^{12}$ da mente, ser acomodado para ver outros objetos a uma distância muito menor; mas

\footnotetext{
${ }^{9}$ Para as diferentes concepções para a luz nos séculos 18 e 19, ver Cantor (1983).

${ }^{10}$ A tradução a seguir foi baseada em Young (1793). Notas dos tradutores são indicadas por [N.T.]. Em algumas das notas, indicamos as alterações feitas por Young na reimpressão desse artigo feitas no volume 2 de $A$ course of Lectures on Natural Philosophy (YOUNG, 1807b). Essa reimpressão contém, segundo ele, algumas correções. As páginas do texto original estão indicadas entre colchetes. Complementos no próprio texto, a fim de facilitar seu entendimento, também foram colocados entre colchetes.

${ }^{11}$ [N.T.] Young havia lido a publicação “An Essay upon Distinct and Indistinct vision” (JURIN, 1738, p. 115), a qual esclarece o significado de visão distinta: "diz-se que um objeto é visto distintamente quando seus contornos parecem claros e bem definidos, e as várias partes dele, senão muito pequenas, são plenamente distinguíveis, de modo que podemos compará-las entre si, com respeito à sua figura, tamanho e cor."

12 [N.T.] O termo "volição" se refere ao poder de escolha. Estudos recentes argumentam que, na Grã-Bretanha do período, o pensamento acerca da volição era altamente influenciado pelo contexto social e educacional do
} 
como essa acomodação é efetuada tem sido há tempos um tópico em discussão, e ainda não foi satisfatoriamente explicada. É igualmente verdade, embora não comumente observado, ${ }^{13}$ que nenhum esforço da mente pode acomodar o olho para ver objetos a uma distância maior que a da visão indolente, como pode ser facilmente experienciado por qualquer pessoa na qual essa distância de visão indolente é menor que infinita.

As partes principais do olho e de seus complementos têm sido descritas por vários autores. Winslow ${ }^{14}$ é geralmente muito preciso; mas Albinus, no Introductio de Musschenbroek, ${ }^{15}$ descreveu várias particularidades mais corretamente. Pressuporei que a descrição deles é completa, exceto onde menciono ou delineio o contrário.

A primeira teoria que eu encontro sobre a acomodação do olho é a de Kepler. Ele supõe que os processos ciliares contraem o diâmetro do olho e aumentam seu eixo por meio de um poder muscular. ${ }^{16}$ Mas, os processos ciliares não parecem conter quaisquer fibras musculares, nem possuem qualquer ligação pela qual eles possam ser capazes de executar essa ação.

Descartes ${ }^{17}$ imaginou que a mesma contração e alongamento fossem efetuados por uma musculatura do cristalino, ${ }^{18}$ da qual ele supôs os processos ciliares serem os tendões. Ele não tentou demonstrar [a existência d] essa musculatura, tampouco considerou suficientemente a conexão com os processos ciliares. Ele afirma que a lente nesse meio tempo se torna mais convexa, mas ${ }^{19}$ atribui muito pouco a essa circunstância.

De La Hire mantêm que o olho não sofre mudança, exceto a contração e dilatação da pupila. Ele não tenta confirmar essa opinião por demonstração matemática, somente a baseia num experimento que foi mostrado ser falacioso por Dr. Smith. ${ }^{20}$ Haller também adotou essa opinião, não obstante o quão inconsistente ela parecesse ser com os princípios conhecidos da óptica e com a menor correspondência com as experiências atuais.

Dr. Pemberton supõe que o cristalino contém fibras musculares, pelas quais uma de suas superfícies é achatada enquanto a outra é feita mais convexa. ${ }^{21}$ Mas, além de [Pemberton] não

indivíduo (BUCHWALD; JOSEFOWICZ, 2020). Para o estudo da acomodação, menções sobre a volição indicam que o processo não era visto como completamente involuntário.

${ }^{13}$ [N.T.] Na reimpressão, Young especificou que Porterfield havia feito essa observação (YOUNG, 1807b, p. 523).

${ }^{14}$ [N.T.] Young se referiu à obra Exposition anatomique de la structure du corps humain (1732). Esse texto também foi traduzido ao latim e ao inglês. Para mais sobre Winslow, ver Saad (2021).

15 [N.T.] O livro consultado por Young foi Introductio ad philosophiam naturalem, publicado em 1762. Esse livro conta com as descrições anatômicas de Albinus.

16 [N.T.] Kepler propôs em seu "Dioptrice" (1611) que a contração muscular dos processos ciliares puxaria as partes laterais do olho para dentro (de JONG, 2020, p. 99). Isso resultaria no aumento da distância entre a lente e a retina, e consequentemente numa alteração no foco da figura.

${ }^{17}$ [N.T.] Referência à teoria proposta por Descartes no Dióptrica (1637). Nessa publicação, Descartes afirmou que pequenos filamentos (os processos ciliares) alterariam o formato do cristalino. Segundo ele, a acomodação também envolvia mudanças na pupila e no formato do olho como um todo.

18 [N.T.] Young aparenta ter se confundido, pois em nenhum momento Descartes atribuiu uma musculatura ao cristalino, mas sim aos processos ciliares e à pupila. Não está claro se Young possuía o texto original de Descartes, ou se leu sobre essa teoria por meio de outro autor.

${ }^{19}$ [N.T.] Na reimpressão, Young especifica que Descartes "não parece atribuir, em sua Dióptrica, qualquer efeito material a essa mudança [alteração na convexidade]". Entretanto, afirma que em "O Tratado do Homem" (1633), Descartes "explica a operação muito detalhadamente" (YOUNG, 1807b, p. 523-524).

${ }^{20}$ [N.T.] Na reimpressão, Young adicionou que Porterfield também apresentou objeções a esse experimento (YOUNG, 1807b, p. 524).

${ }^{21}$ [N.T.] Em sua dissertação médica publicada ao se formar na Universidade de Leiden (1719), Pemberton afirmou que a própria lente era muscular, sendo constituída de dois músculos opostos, capazes de achatá-la em um dos lados e torná-la mais convexa no outro (OSBORNE, 1979, p. 102). 
ter demostrado [a existência de] tais fibras, ${ }^{22}$ Dr. Jurin provou que uma mudança como essa é inadequada para o efeito. ${ }^{23}$

Dr. Porterfield concebe que os processos ciliares trazem o cristalino para a frente e tornam a córnea mais convexa. ${ }^{24}$ Os processos ciliares são, por sua estrutura, ligação e direção, completamente incapazes dessa ação. Pelos cálculos de Dr. Jurin, não há espaço para um movimento suficiente desse tipo sem um aumento muito visível do eixo do olho. ${ }^{25}$ Tal aumento não podemos observar.

A hipótese de Dr. Jurin é a de que a úvea, em sua ligação à córnea, é muscular, e que a contração desse anel torna a córnea mais convexa. Ele diz que as fibras desse músculo podem escapar da nossa observação tão bem quanto aquelas do músculo do anel interior. ${ }^{26}$ Mas, se tal músculo existisse, ele deveria, para superar a resistência das camadas, ser muito mais forte do que aquele que é apenas destinado à própria úvea. A úvea, nessa parte, exibe nada além de fibras radiadas, perdendo-se antes do círculo de aderência à esclerótica, em uma substância granulada e acastanhada, semelhante em aparência ao ligamento capsular, comum à úvea e aos processos ciliares, mas que pode ser distinguida separadamente de ambos. Agora, no anel interior da úvea, a aparência não é absolutamente inconsistente com a de um músculo anular. ${ }^{27}$ Sua teoria de acomodação para objetos distantes é engenhosa, mas tal acomodação não acontece.

Musschenbroek especula que o relaxamento de sua zona ciliar, ${ }^{28}$ que aparenta não ser nada além do que a cápsula do humor vítreo onde recebe a impressão dos processos ciliares, permite que as camadas do olho empurrem para a frente o cristalino e a córnea. Tal relaxamento voluntário é completamente sem precedentes na economia animal, e, se acontecesse, as camadas do olho não agiriam como ele imagina, nem poderiam agir sem serem notadas. A contração da zona ciliar é igualmente inadequada e desnecessária.

Alguns têm suposto que a pressão dos músculos externos, especialmente dos dois músculos oblíquos, ${ }^{29}$ alonga o eixo do olho. Mas, sua ação não seria suficientemente regular, nem suficientemente forte; pois, [no caso de] uma pressão muito maior sendo feita no olho do

\footnotetext{
22 [N.T.] Pemberton não demonstrou a existência de fibras musculares, mas nesse artigo Young também não o fez. Talvez por essa razão, a crítica a Pemberton foi removida do texto reimpresso.

23 [N.T.] Jurin argumenta que, caso a teoria de Pemberton estivesse correta, ao observar um objeto a uma distância de 14 pés e 5 polegadas, o raio da superfície anterior do cristalino deveria ser dobrado, e o raio da outra superfície diminuído por um terço (JURIN, 1738, p. 137). A consistência do cristalino não lhe permitiria sofrer tamanha mudança. Portanto, a alteração no foco não poderia ser atribuída a uma deformação similar àquela proposta por Pemberton.

24 [N.T.] Porterfield propôs que uma musculatura do ligamento ciliar empurraria a lente para a frente, aumentando assim a distância entre a lente e a retina (PORTERFIELD, 1759, p. 446-447).

25 [N.T.] Jurin afirma que a distância entre o cristalino e a úvea é de 0,22 polegadas, e que para observar objetos a uma distância de 14 pés e 5 ou 6 polegadas, seria necessário que o cristalino se deslocasse 0,87 polegadas (JURIN, 1738, p. 137).

${ }^{26}$ [N.T.] Anel interior refere-se ao anel da úvea responsável pela contração da pupila, cuja musculatura era geralmente tida como certa. A alteração de forma da pupila é facilmente observável, porém nenhum anatomista havia sido capaz de demonstrar tal musculatura (JURIN, 1738, p. 138). Jurin propôs a existência de outro músculo agindo nessa região, e afirmou que as fibras musculares desse músculo podiam escapar da observação assim como as fibras do anel interior.

27 [N.T.] Em formato de anel.

28 [N.T.] Na reimpressão, Young mencionou que a zona ciliar foi nomeada por Zinn (YOUNG, 1807b, p. 524).

29 [N.T.] Os músculos oblíquos são músculos extraoculares, com a função de mover ou rotacionar o olho (WRIGHT, 2003, p. 24-29).
} 
que eles [os músculos] podem concebivelmente ser capazes de efetuar, nenhuma diferença sensível é produzida na clareza da visão. ${ }^{30}$

Outros dizem que os músculos encurtam o eixo. Por sua vez, esses [autores] possuem ainda menos razão. ${ }^{31}$

Aqueles que mantêm que os processos ciliares achatam ${ }^{32}$ o cristalino são ignorantes de sua estrutura e do efeito necessário. Esses processos são ainda mais incapazes de trazer o cristalino de volta para trás, ${ }^{33}$ e tal ação é igualmente inconsistente com a observação.

Provavelmente, outras suposições podem ter sido feitas, sujeitas a objeções tão fortes quanto as opiniões que eu listei. ${ }^{34}$

A partir dessas considerações, e pela observação do Dr. Porterfield, de que aquelas [pessoas] que foram declinadas ${ }^{35}$ não possuem mais o poder de acomodar o olho a diferentes distâncias, ${ }^{36}$ eu havia concluído que os raios de luz emitidos por objetos a uma distância pequena poderiam ser trazidos ao foco na retina apenas por uma formação do cristalino [de modo a torná-lo] mais próximo a uma figura esférica. Eu não poderia imaginar outro poder capaz de produzir essa mudança do que uma musculatura de uma parte, ou da totalidade, de sua cápsula. ${ }^{37}$

Contudo, ao examinar detalhadamente o cristalino de um boi, removido de sua cápsula, com o olho nu sob uma luz forte, descobri uma estrutura que aparenta superar todas as dificuldades com as quais esse ramo da óptica tem sido obscurecido por muito tempo. Ao vêla com uma lupa, essa estrutura se tornou mais evidente.

A lente cristalina do boi é um corpo orbicular, convexo e transparente, composto de um número considerável de camadas similares, das quais a exterior adere muito proximamente à interior. Cada uma dessas camadas consiste de seis músculos misturados com uma substância gelatinosa e ligados a seis tendões membranosos. Três dos tendões são anteriores, três posteriores. Seus tamanhos são aproximadamente dois terços do semidiâmetro da camada; seus arranjos são aqueles de três raios iguais e equidistantes, encontrando-se no eixo do cristalino; um dos [tendões] anteriores é direcionado rumo ao ângulo externo do olho, e um dos posteriores

\footnotetext{
${ }^{30}$ [N.T.] Por exemplo, ao aplicar com os dedos certa pressão sobre o olho, o foco da visão não é alterado de maneira significativa. Young acreditava que os músculos oblíquos não seriam capazes de exercer uma pressão tão forte quanto essa. Logo, concluiu que eles não poderiam ser responsáveis pela acomodação, já que sua pressão seria insuficiente.

${ }^{31}$ [N.T.] Na reimpressão do artigo, ele complementou: "já que tal mudança aumentaria a distância focal, que na verdade é maior quando o olho está em repouso" (YOUNG, 1807b, p. 524). Young evidentemente acreditava que a acomodação consistia do processo contrário, o de diminuição da distância focal.

32 [N.T.] Similarmente ao encurtamento o eixo ocular, o achatamento do cristalino aumentaria a distância focal.

33 [N.T.] Essa é uma referência à teoria de Porterfield, que pressupunha o cristalino sendo empurrado pelos processos ciliares.

${ }^{34}$ [N.T.] Na reimpressão, Young expandiu esse parágrafo, discutindo outras teorias de acomodação e rejeitandoas (YOUNG, 1807b, p. 525).

35 [N.T.] O termo original utilizado por Young foi "couched", em referência à técnica conhecida como "couching". Trata-se de uma forma de cirurgia utilizada para tratar cataratas, onde a lente opaca é movida de lugar ou removida. Caso fosse realizada com sucesso, o paciente recuperava sua visão. Um exemplo foi descrito pelo cirurgião William Chesselden (1688-1752) nas Philosophical Transactions da Royal Society (CHESSELDEN, 1727).

${ }^{36}$ [N.T.] Porterfield havia observado que pacientes cujo cristalino fora removido durante a cirurgia de catarata perdiam seu poder de acomodação. Em teorias como a de Kepler, onde a mudança não envolvia diretamente o cristalino, a ausência dele não deveria afetar o poder acomodativo do indivíduo. Portanto, essa observação sugeria fortemente o protagonismo do cristalino no processo acomodativo.

37 [N.T.] Era conhecido que a lente cristalina era envolta por uma cápsula membranosa de poder refrativo similar, ambas separadas por um líquido (JURIN, 1738, p. 139). É importante ressaltar que uma das objeções de Porterfield para a musculatura do cristalino era que esse não possuía qualquer conexão física com sua cápsula, sendo, portanto, incapaz de receber a vontade da mente (PORTERFIELD, 1759, p. 443). Contudo, as observações de Albinus, das quais Young estava ciente, indicavam a existência de tal conexão (PRIESTLEY, 1772, p. 187).
} 
rumo ao ângulo interno, de forma que os posteriores são localizados opostos ao meio dos interstícios dos anteriores; e planos passando por cada um dos seis [tendões] e através do eixo marcam em cada superfície seis raios equidistantes regulares. As fibras musculares surgem de ambos os lados de cada tendão. Elas se separam até chegar à maior circunferência da camada, e, tendo passado por ela, convergem novamente, até serem ligadas respectivamente aos lados dos tendões da superfície oposta [que estão] mais próximos a elas. A porção anterior ou posterior das seis [fibras], quando vistas juntamente, exibe a aparência de três músculos radiados de maneira peniforme. ${ }^{38}$ Os tendões anteriores de todas as camadas são situados nos mesmos planos, e os posteriores nas continuações desses planos além do eixo. Tal arranjo de fibras pode ser explicado por nenhuma outra suposição além da [existência de uma] musculatura. Essa massa é envolvida em uma forte capsula membranosa, à qual é folgadamente conectada por veias e nervos diminutos; e a conexão é mais observável perto de sua maior circunferência. ${ }^{39}$ Entre a massa e a sua cápsula, é encontrada uma quantidade considerável de um fluido aquoso, o líquido do cristalino.

Eu penso, portanto, que quando a vontade para observar um objeto a uma distância pequena é manifestada, a influência da mente é transmitida pelo gânglio lenticular - formado das ramificações do terceiro e do quinto par de nervos, pelos filamentos perfurando a esclerótica até o orbículo ciliar -, que pode ser considerado como um plexo anular de nervos e veias; e então pelos processos ciliares ao músculo do cristalino, que, pela contração de suas fibras, se torna mais convexo e coleta os raios divergentes a um foco sobre a retina. A disposição de fibras em cada camada [do cristalino] é admiravelmente adaptada para produzir essa mudança, pois, já que a menor superfície que pode conter uma dada quantidade é a de uma esfera (Simpson's Fluxions, p. 486), a contração de qualquer superfície deve tornar seu conteúdo mais próximo de uma forma esférica. ${ }^{40} \mathrm{O}$ líquido do cristalino parece servir como um líquido sinovial, ao facilitar o movimento, e admitir uma mudança suficiente da parte muscular, com um movimento menor da cápsula.

Resta ser investigado se essas fibras podem produzir uma alteração na forma da lente suficientemente grande para ser responsável pelos efeitos conhecidos.

No olho de boi, o diâmetro do cristalino é 700 milésimos de uma polegada, o eixo de seu segmento anterior, 255, de seu posterior, 350. Na atmosfera, coleta raios paralelos a uma distância de 235 milésimos. A partir desses dados, encontramos, por meio do Optics de Smith, ${ }^{41}$ Art. 366, e uma quadrática, que sua razão de refração é de 10000 para 6574 . Hauksbee ${ }^{42}$ a faz apenas como 10000 para 6832,7, mas não podemos depender de seu experimento, já que ele diz que a imagem da vela que observou estava alargada e distorcida, ${ }^{43}$ uma circunstância que

\footnotetext{
${ }^{38}$ [N.T.] Em forma de pena.

${ }^{39}$ [N.T.] Assim como Albinus, Young afirmou que o cristalino está conectado à sua capsula.

${ }^{40}$ [N.T.] Referência ao tratado The Doctrine and Application of Fluxions (1750), do matemático inglês Thomas Simpson (1710-1761). O corolário utilizado (SIMPSON, 1750, p. 485-486) afirma que a menor curva que contém uma dada área deve ser o arco de uma circunferência. Aqui, Young utiliza isso de maneira engenhosa, implicitamente generalizando o corolário para três dimensões e tomando sua forma recíproca: dada uma superfície de área conhecida, a maximização do volume contido por ela ocorre quando a superfície segue a equação de uma esfera. Assim, com o pressuposto de que o volume total se mantém constante, a diminuição de uma superfície (por contração muscular) implica no aumento de sua esfericidade.

${ }^{41}$ [N.T.] O livro referido é o A Compleat System of Opticks. Dentre os assuntos trabalhados nessa obra, estão diversas proposições geométricas voltadas à resolução de problemas ópticos. Para mais detalhes, ver Steffens (1977).

42 [N.T] Francis Hauksbee (1666-1713). Young cita os dados disponíveis no livro Physico-Mechanical experiments on various subjects (HAUKSBEE, 1719, p. 293).

43 [N.T.] Hauksbee utilizou um prisma e um sextante para determinar diversos índices refrativos. Para medir o índice do olho de boi, Hauksbee foi "[...] obrigado a utilizar uma vela para esse fim, a chama da qual apareceu muito larga, pelo menos cinco ou seis polegadas, quase na forma de uma meia-lua. Mas o que deveria ocasionar
} 
ele não explica, mas que foi evidentemente ocasionada pela maior densidade das partes centrais. Supondo, como Hauksbee e outros, que a refração dos humores aquoso e vítreo é igual à da água, a saber, de 10000 para $7465,{ }^{44}$ a razão de refração do cristalino no olho seria de 10000 para $8806,{ }^{45}$ e ele coletaria raios paralelos a uma distância de 1226 milésimos de uma polegada. Mas, a distância da retina ao cristalino é de 550 milésimos, e aquela da superfície anterior da córnea, 250. Consequentemente, (por Smith, Art. 367;) a distância focal da córnea e do humor aquoso sozinhos deve ser de 2329 [milésimos]. Agora, supondo que o cristalino assuma uma forma esférica, seu diâmetro será de 642 milésimos e sua distância focal no olho de 926 . Então, desconsiderando a espessura da córnea, descobrimos (por Smith, Art. 370) que tal olho coletará esses raios na retina, os quais divergem de um ponto a uma distância de 12 polegadas e 8 décimos. Isso é uma mudança maior do que é necessário para um olho de boi, pois se for suposto ser capaz de [possuir] visão distinta a uma distância mais ou menos menor que 12 polegadas, ainda é provavelmente muito longe de ser capaz de coletar raios paralelos. O cristalino humano é suscetível a uma mudança de forma muito maior. ${ }^{46}$

A zona ciliar pode admitir tanta extensão quanto essa diminuição do diâmetro do cristalino requirirá. Sua elasticidade auxiliará a textura celular do humor vítreo - e talvez a parte gelatinosa do cristalino - a restaurar a forma indolente. ${ }^{47}$

Pode ser questionado se a retina desempenha algum papel em suprir a lente com nervos. Mas, pela analogia dos nervos olfatórios e auditivos, parece mais razoável supor que o nervo óptico não tenha qualquer outro propósito senão o de transmitir sensações ao cérebro.

Embora sejam necessários uma forte luz e um exame próximo para ver as fibras do cristalino em seu estado inteiro, ainda assim suas direções podem ser demonstradas, e seus ligamentos mostrados, sem muita dificuldade. Em um olho morto, os tendões são discerníveis através da cápsula, e às vezes os anteriores [são discerníveis] mesmo através da córnea e do humor aquoso. Quando o cristalino cai, muito frequentemente se separa tão longe quanto possível do centro, em três porções, cada [uma] possuindo um tendão em seu meio. Se for cuidadosamente despido de sua cápsula, e for aplicado um forte assopro de uma boa zarabatana $^{48}$ perto de sua superfície em partes diferentes, será visto que ele se despedaça exatamente na direção das fibras descritas acima, e todas essas rachaduras serão paradas assim que chegarem a qualquer um dos tendões. A aplicação de um pouco de tinta no cristalino é de grande uso para mostrar o curso das fibras.

tal mudança de figura, eu não posso determinar no momento presente.” (HAUKSBEE, 1719, p. 291). Nesse trecho, Young afirma que tal alargamento ocorre devido à densidade não-uniforme do cristalino, o qual é mais denso próximo do centro.

44 [N.T.] Possivelmente, temos aqui um erro tipográfico. A razão exata estabelecida por Hauksbee é de 10000 para 7485.3. Como mencionado por Porterfield, isso equivale a aproximadamente 4 para 3 (PORTERFIELD, 1759, p. 283).

45 [N.T.] A razão de 10000 para 8806 equivale a 1.135, truncando a expansão decimal em sua terceira casa. Esse valor é significativamente diferente do índice refrativo encontrado por outros autores. De acordo com William Hyde Wollaston (1766-1828), o índice refrativo do cristalino de boi está entre 1.447 e 1.380, enquanto para Tiberius Cavallo (1749-1809), o valor é 1.463 (YOUNG, 1807b, p. 297). Em "On the Mechanism of the Eye", Young explicou alguns dos motivos que resultaram nessa divergência entre os autores (YOUNG, 1801, p. 4143).

${ }^{46}$ [N.T.] Nesse parágrafo, Young utilizou a óptica geométrica para verificar se um aumento de esfericidade seria suficiente para explicar a acomodação no olho de boi. O resultado foi positivo, e ele então generalizou essa conclusão para o cristalino humano.

47 [N.T.] Como o papel do músculo é apenas se contrair, a restauração do formato original do cristalino deveria ser efetuada de alguma outra maneira. Aqui, Young afirmou que a elasticidade da zona ciliar contribuiria para esse processo.

48 [N.T.] Winslow descreveu o mesmo procedimento em seu tratado anatômico. 
Quando eu observei a estrutura do cristalino pela primeira vez, eu não estava ciente que sua musculatura já havia sido suposta. Nós vimos, porém, que Descartes a supôs ser dessa natureza. ${ }^{49}$ Mas, ele parece pensar que a acomodação do olho a uma distância pequena é principalmente efetuada pelo alongamento de seu eixo. De fato, assim como um sino faz tremer um campanário, também devem as camadas do olho ser afetadas por qualquer mudança no cristalino. Porém, o efeito disso será muito insignificante. Ainda, uma vez que isso acontece, cooperará com a outra alteração.

Mas o dedicado e preciso Leeuwenhoek, com ajuda de seus potentes microscópios, descreveu o curso das fibras do cristalino em uma variedade de animais. Ele ainda foi longe o bastante ao chamá-lo de músculo. ${ }^{50}$ Porém, ninguém avançou na sugestão, e provavelmente por esta razão, a de examinar somente preparações secas, ele imaginou que cada camada consistisse da circunvolução de uma única fibra e deixou passar completamente o ligamento das fibras aos tendões. Se as fibras fossem continuadas umas nas outras da maneira que ele descreve, a analogia estrita com músculo seria perdida e suas contrações não poderiam ter aquele efeito na figura da lente, que é produzida com a ajuda dos tendões. Ainda assim, nem ele nem qualquer outro fisiologista tentou explicar a acomodação do olho a diferentes distâncias por meio dessas fibras. Não obstante, muito mérito anatômico deve ser dado pela descrição fiel e delineação elegante dos cristalinos de vários animais que ele ofereceu nas Philosophical Transactions, Vol. XIV. p. 780, e Vol. XXIV. p. 1723. Parece, por suas descrições e figuras, que o cristalino de porcos, cachorros e gatos é semelhante ao que eu observei em bois, ovelhas e cavalos; que, em lebres e coelhos, os tendões em cada lado são apenas dois, encontrando-se em linha reta no eixo; e que, em baleias, eles são cinco, radiados da mesma maneira que onde há três. É evidente que essa variedade não fará diferença material na ação do músculo. Eu ainda não tive a oportunidade de examinar o cristalino humano, mas a partir de sua fácil divisão em três partes, podemos inferir que é similar ao do boi. O cristalino em peixes sendo esférico, ${ }^{51}$ tal mudança que atribuo à lente em quadrupedes não pode acontecer nessa classe de animais.

Tem sido observado que a parte central do cristalino se torna rígida pela idade, e isso é suficiente para explicar a presbiopia, ${ }^{52}$ sem qualquer diminuição dos humores, embora eu não negue a existência dessa diminuição como uma circunstância concomitante.

Eu devo aqui pedir permissão para tentar solucionar algumas questões ópticas que não têm sido muito consideradas por [outros] autores.

1. Musschenbroek pergunta, qual é a causa das radiações laterais que parecem aderir a uma vela observada com olhos quase fechados? Eu digo [que] as radiações mais visíveis são aquelas que, divergindo por baixo, formam, cada uma com uma linha vertical, um ângulo de aproximadamente 7 graus. Esse ângulo é igual àquele que os cantos das pálpebras quando fechadas fazem com uma linha horizontal. E as radiações são evidentemente causadas pela reflexão de luz a partir desses cantos achatados. As radiações laterais são produzidas pela luz

\footnotetext{
49 [N.T.] Na reimpressão, Young adicionou: “ele [Descartes], porém, não tinha uma ideia precisa de sua [do cristalino] estrutura interna". (YOUNG, 1807b, p. 527).

${ }^{50}$ [Young, citando um trabalho de Leeuwenhoek] Agora, se o humor cristalino (que eu tenho algumas vezes chamado de músculo cristalino) em nossos olhos, \&c. Phil. Trans. Vol. XXIV. p. 1727 - Crystallinum musculum, alias humorem crystallinum dictum, \&c. Leeuwenh. op. omn. I. p. 102.

${ }^{51}$ [N.T.] A acomodação proposta por Young ocorre quando o cristalino se torna mais esférico. Um cristalino naturalmente esférico não poderia ser acomodado dessa maneira.

52 [N.T.] A presbiopia é a perda de poder acomodativo que ocorre naturalmente com a idade, pois a lente se torna progressivamente mais inflexível. Smith afirmou que o decaimento natural da visão era ocasionado pela diminuição dos humores oculares, o que resultaria no achatamento da córnea e cristalino (SMITH, 1738, p. 27). Assim como na discussão acerca do alongamento do eixo ocular, Young não excluiu completamente a possibilidade dessa alteração ocorrer, mas deixou claro nesse parágrafo que sua teoria de preferência era a mudança de rigidez do cristalino.
} 
refletida dos cantos das partes laterais da margem pupilar da úvea, enquanto suas porções superiores e inferiores são cobertas pelas pálpebras. Sendo a úvea inteira escondida antes do fechamento total das pálpebras, essas radiações horizontais desaparecem antes das perpendiculares. ${ }^{53}$

2. Alguns têm questionado: de onde surge aquela cruz luminosa que aparenta proceder da imagem de uma vela em um espelho? Isso é produzido pela direção da fricção pela qual o vidro é polido. Os arranhões localizados em uma direção horizontal, exibindo a parte perpendicular da cruz, e os arranhões verticais [exibindo] a parte horizontal, de uma maneira que pode ser facilmente concebida.

3. Por que parecem ser emitidas faíscas quando o olho é esfregado ou comprimido no escuro? Isso é a quarta questão de Musschenbroek. ${ }^{54}$ Quando uma pressão ampla, como aquela do dedo, é feita na parte opaca do olho no escuro, um espectro orbicular aparece na parte oposta àquela que é pressionada. A luz do disco é fraca, aquela da circunferência é muito mais forte. Mas, quando uma superfície estreita é aplicada, como a de uma cabeça de alfinete, ou da unha, a imagem é estreita e brilhante. Isso é evidentemente ocasionado pela irritação da retina na parte tocada, reportada pela mente ao local onde a luz vinda através da pupila cairia nesse ponto. ${ }^{55} \mathrm{~A}$ irritação é maior onde a curvatura é maior, isto é, na circunferência e às vezes no centro da parte achatada. Mas, na presença da luz, esteja o olho aberto ou fechado, apenas a circunferência será luminosa, e o disco escuro. Se o olho estiver vendo qualquer objeto na parte onde a imagem aparece, esse objeto será totalmente invisível. Daí segue que a tensão e compressão da retina destrói toda a irritação, exceto aquela que é produzida por sua curvatura. Isso é tão insignificante no disco, que a luz ali aparente é mais fraca que aquela dos raios chegando a todas as outras partes através das pálpebras. Esse experimento demonstra uma verdade, que pode ser inferida de muitos outros argumentos, e é de fato quase um axioma, a saber, que a suposta correção da imagem invertida na retina ${ }^{56}$ não depende da direção dos raios incidentes. Newton, em sua décima sexta questão, ${ }^{57}$ descreveu essa aparição [como sendo de] de cores pavonianas, ${ }^{58}$ mas eu consigo distinguir nenhuma outra além de branco. Parece mais natural que isso - sendo a mistura ou a média de todas as sensações existentes de luz - devesse ser produzida quando nada indica qualquer cor particular. Essa média parece lembrar a forma intermediária que Sir Joshua Reynolds ${ }^{59}$ elegantemente abordou em seus discursos, tal que

\footnotetext{
53 [N.T] Em seu artigo posterior sobre o tema, "On the mechanism of the eye" (1801), Young retornou a essa questão, dessa vez afirmando que o fenômeno é causado por reflexões nos cílios.

${ }^{54}$ [N.T.] A quarta questão de Musschenbroek diz respeito à percepção da luz que ocorre quando se pressiona 0 globo ocular no escuro. Musschenbroek atribuiu tal fenômeno ao efeito do suposto fluido elétrico presente nos humores oculares.

55 [N.T.] Em outras palavras, essa irritação na retina seria interpretada como um estímulo visual.

56 [N.T.] De acordo com a óptica geométrica, os raios luminosos necessariamente se cruzariam dentro do olho e a imagem na retina se formaria de maneira invertida. Porém, percebemos as imagens na orientação correta, e isso deveria ser explicado. Kepler, Descartes e outros consideravam que a questão era parte da óptica psicológica, fora do escopo da óptica física. Similarmente, no volume 1 do Lectures, Young afirmou que a imagem na retina é invertida devido às "leis comuns da refração", e tentou explicar de maneira psicológica como ocorre a percepção na orientação correta (YOUNG, 1807a, p. 448). Posteriormente, experimentos como os de George M. Stratton (1865-1957) buscaram demonstrar que o processo é de fato psicológico (SACHSE et al., 2017).

57 [N.T.] A Questão 16 do Óptica menciona o mesmo fenômeno que a quarta questão de Musschenbroek. Nessa questão, Newton descreveu que "quando um homem no escuro pressiona qualquer canto dos olhos com o dedo e move o olho em direção oposta ao dedo, vê um círculo de cores como as da pena da cauda de um pavão" e que essas cores desaparecem se o olho e o dedo "permanecem quietos" (NEWTON, 1996, p. 256). Newton explicou esse fenômeno supondo que a pressão e movimento do dedo provocam movimentos na retina, e que esse movimento tem natureza vibratória.

58 [N.T.] Referente às cores das penas de um pavão.

${ }^{59}$ [N.T.] Sir Joshua Reynolds (1723-1792), próspero pintor inglês. Era conhecido de Young, devido à sua amizade com Richard Brocklesby. Em seus discursos, Reynolds argumentava que maior beleza na arte era alcançada
} 
porventura alguns princípios do bonito contraste entre cores possa ser desenhado daí, sendo provável que aquelas cores que juntas se aproximam da luz branca terão os efeitos mais agradáveis de justaposição. Deve ser observado que a sensação de luz a partir da pressão do olho retrocede quase instantaneamente após o movimento de pressão cessar, tal que a causa da irritação da retina é uma mudança de forma, e não uma diferença. ${ }^{60}$ Portanto, a sensação da luz parece depender imediatamente de um movimento diminuto de alguma parte do nervo ótico.

Se a parte anterior do olho for repetidamente pressionada, de modo a ocasionar algum grau de dor, e uma pressão contínua for então feita na esclerótica, enquanto uma pressão interrupta é feita na córnea, devemos frequentemente ser capazes de observar o surgimento de linhas luminosas ramificadas e um tanto quanto conectadas entre si, propelidas de toda parte do campo de visão rumo a um centro um pouco exterior e superior ao eixo do olho. ${ }^{61}$ Esse centro corresponde à inserção do nervo ótico, e a aparição de linhas é provavelmente ocasionada por aquele movimento da retina que é produzido pelo retorno súbito do fluido circulatório para as veias que acompanham as ramificações da artéria central, após terem sido detidas pela pressão a qual agora é interrompida. Como tal obstrução e tal readmissão devem requisitar circunstâncias particulares para serem efetuadas a um grau sensível, pode ser naturalmente suposto que esse experimento nem sempre será facilmente realizado com sucesso.

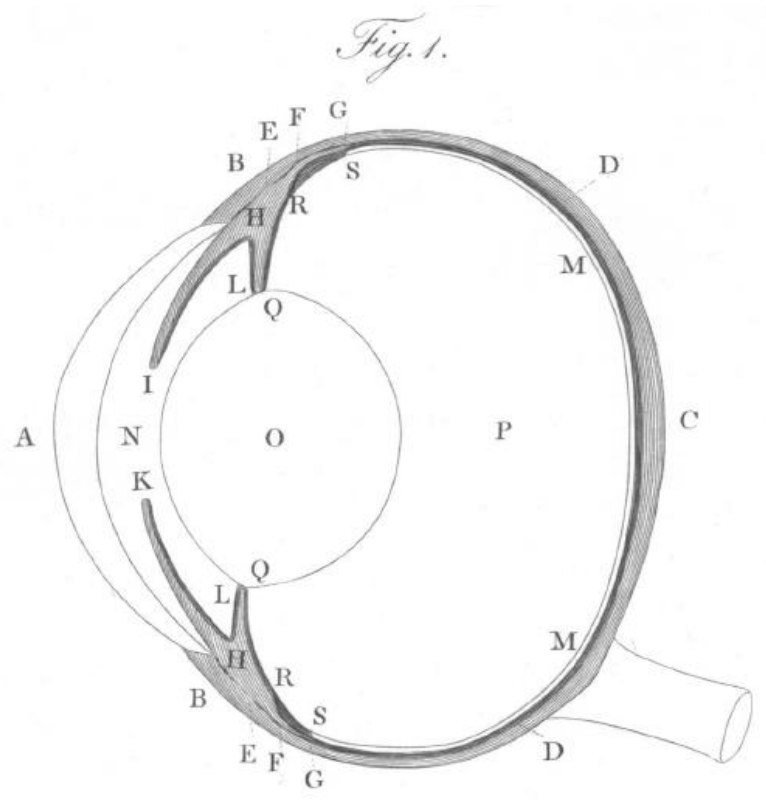

Figura 3 - Ilustração inserida no final do "Observations on vision" (1793). Na legenda, lê-se: "TAB. XX. fig.1. Uma seção vertical do olho de boi, duas vezes seu tamanho natural. (A) córnea, coberta pela tunica conjunctiva; $(\mathrm{BCB})$ a esclerótica, coberta em $\mathrm{BB}$ pela tunica albugínea, e tunica conjunctiva; (DD) a coroide, consistindo de duas laminas; (EE) o círculo de

quando eram mesclados os "detalhes de objetos individuais em efeito geral", como uma forma intermediária ou "ideia abstrata de uma certa classe" (HAZLITT, 2002, p. 211). Tal teoria teve opositores, como o crítico literário e pintor William Hazlitt (1778-1830). Hazlitt o critica em uma de suas dissertações, afirmando que Reynolds não misturaria as cores do arco íris para produzir um cinza de modo a alcançar maior beleza (Ibid, p. 211). Ironicamente, Young propôs exatamente essa mistura, porém, tomando a cor branca como sendo a média das cores ao invés do cinza de Hazlitt. O crítico estava pensando em termos de pigmentos; Young, nas cores espectrais.

${ }^{60}$ [N.T.] Se a irritação fosse causada por uma diferença de forma, a sensação de luz permaneceria até a pressão ser removida. Seguindo raciocínio similar, Erasmus Darwin propôs em Zoonomia (DARWIN, 1794) que a percepção de visual era resultado de um movimento no órgão da visão.

61 [N.T.] O nervo óptico não é alinhado ao eixo ocular. 
aderência da coroide à esclerótica; (FG, FG) o orbiculus ciliaris; (HI, HK) a úvea: sua superfície anterior [é] a íris, sua superfície posterior é [lined] com pigmentum nigrum; (IK) a pupila; (HL, $\mathrm{HL}$ ) os processos ciliares, cobertos com pigmentum nigrum; (MM) a retina; $(\mathrm{N})$ o humor aquoso; (O) a lente cristalina; (P) o humor vítreo; (QR, QR) a zona ciliaris; (RS, RS) o annulus тисоsи".
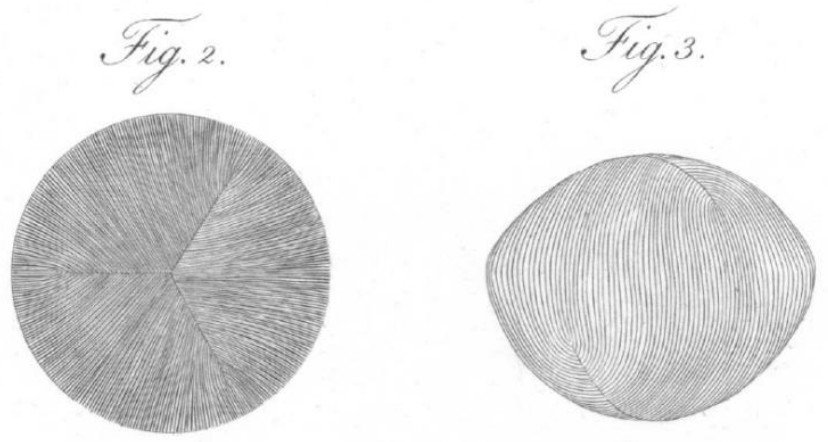

Figura 4 - Outras ilustrações inseridas no final do "Observations on vision" (1793). Nas legendas, lê-se: "(Fig. 2). A estrutura da lente cristalina, vista de frente. (Fig. 3). Uma vista de lado do cristalino"

Fonte: Young (1793, p. 181)

\section{Agradecimentos}

Agradecemos o apoio do Conselho Nacional de Desenvolvimento Científico e Tecnológico (CNPq-PIBIC) e da Fundação de Amparo à Pesquisa do Estado de São Paulo (processo ${ }^{\circ}$ 2021/07238-9) para a realização deste trabalho.

\section{Referências}

BATES, A. W. H. Vivisection, Virtue Ethics, and the Law in 19th-Century Britain. Journal of Animal Ethics, v. 4, n. 2, p. 30-44, 2014.

BUCHWALD, J; JOSEFOWICZ, D. The Riddle of the Rosetta: How an English Polymath and a French Polyglot Discovered the Meaning of Egyptian Hieroglyphs. Princeton: Princeton University Press, 2020.

BURROWS, R. The Anatomy Act of 1822: The Story of Bodysnatching, Dissections, and the Rise of Anatomy. Tenor of Our Times, v. 9, p. 24-45, 2019.

CANTOR, G. N. Optics after Newton: Theories of light in Britain and Ireland, 1704-1840. Manchester: Manchester University Press, 1983. 
CHESSELDEN, W. An account of some observations made by a young gentleman, who was born blind, or lost sight so early, that he had no remembrance of ever having seen, an was between 13 and 14 years of age. Philosophical Transactions of the Royal Society, v. 35, p. 447-450, 1728.

DALTON, J. Extraordinary Facts relating to the Vision of Colours. Memoirs of the Literary and Philosophical Society of Manchester, v. 5, p. 28-45, 1798.

DARWIN, E. Zoonomia; or, the Laws of Organic Life, London: 1794.

DESCARTES, R. A Dióptrica. Tradução de José P.S. Ramos. Scientia Studiae, v. 8, n. 3, p. 451-486, 2010.

DESCARTES, R. Discours de la méthode pour bien conduire sa raison \& chercher la vérité dans les sciences. Plus la dioptrique et les météores. Paris: Le Gras, 1658.

Disponível em: <https://www.e-rara.ch/zut/content/zoom/1274616>. Acesso em: 10 out. 2021

GLASSER, A.; HOWLAND, H. C. A history of studies of visual accomodation in birds. The Quarterly Review of Biology, v. 71, n. 4, p. 475-509, 1996.

HARPER, D.G. Bringing Accomodation into Focus: The Several Discoveries of the Ciliary Muscle. JAMA Ophtalmology, v. 132, n. 5, p. 645-8, 2014.

HAUKSBEE, F. Physico-mechanical Experiments on Various Subjects. London: 1719.

HAZLITT, W. Table-Talk: Essays on Men and Manners. Urbana: Project Gutenberg, 2002. Disponível em: <https://www.gutenberg.org/ebooks/3020>. Acesso em: 10 nov. 2021.

HOME, E. The Croonian Lecture on Muscular Motion. Philosophical Transactions of the Royal Society, London, v. 85, p. 1-23, 1795.

HOSACK, D. Observations on Vision. Philosophical Transactions of the Royal Society, London, v. 84, p. 196-216, 1794.

de JONG, P. T. V. M. The quest for the human ocular accomodation mechanism. Acta Ophthalmologica, v. 98, n. 1, p. 98-104, 2020.

JURIN, J. An Essay on Distinct and Indistinct Vision. In: SMITH, R. A Compleat System of Opticks, v. 2. Cambridge: printed for the author, 1738. p. 115-171.

LINDBERG, D. C. Theories of vision from Al-Kindi to Kepler. Chicago/London: The University of Chicago Press, 1976.

LINDBERG, D. C. The Beginnings of Western Science: The European Scientific Tradition in Philosophical, Religious and Institutional Context, Prehistory to A.D. 1450. $2^{\text {nd }}$ ed. Chicago /London: University of Chicago Press, 2008.

LEFFLER, C. T.; HADI, T. M.; UDUPA, A.; SCHWARTZ, S. G.; SCHWARTZ, D. A medieval fallacy: the crystalline lens in the center of the eye. Clinical Ophthalmology, v. 10, p. 649-662, 2016. 
MITCHELL, P. D. et al. The study of anatomy in England from 1700 to the early 20th century. Journal of Anatomy, v. 219, n. 2, p. 91-99, 2011.

MOURA, B. A.; BOSS, S. L. B. Thomas Young e o resgate da teoria ondulatória da luz: uma tradução comentada de sua Teoria sobre Luz e Cores. Revista Brasileira de Ensino de Física, v. 37, n. 4, 4203, 2015.

MUSSELMAN, E. G. Nervous Conditions: Science and the Body Politic in Early Industrial Britain. Albany, NY: State University of New York Press, 2006.

NEWTON, I. Óptica. Trad. André K.T. Assis. São Paulo: EDUSP, 1996.

NEWTON, I. Principia. Livros II e III. Trad. André K.T. Assis. São P aulo: EDUSP, 2008.

OLIVEIRA, R. A.; MARTINS, A. F. P.; SILVA, A. P. B. Thomas Young e a teoria ondulatória da luz no início do século XIX: spectos conceituais e epistemológicos. Revista Brasileira de Ensino de Física, v. 41, n. 2, e20180141, 2019.

OSBORNE, P. M. A History of Physiological Optics, from 1650 to 1800. Unpublished PhD Dissertation. Imperial College of Science and Technology, London, 1979.

OTT, M. Visual accomodation in vertebrates: mechanisms, physiological response and stimuli. Journal of Comparative Physiology, v. 192, n. 2, p. 97-111, 2005.

PEACOCK, G. Life of Thomas Young. London: John Murray, 1855.

PORTERFIELD, W. A treatise on the eye, the manner and phaenomena of vision. Edinburgh: Millar, A; Hamilton, G., 1759.

PRIESTLEY, J. The History and Present State of Discoveries Relating to Vision, Light, and Colours. London: printed for J. Johnson, 1772.

SAAD, T. C. Jacob Winslow (1669-1760): The surprising legacy of an anatomist. Journal of Medical Biography, v. 29, n. 3, p. 124-131, 2021.

SACHSE, P.; BEERMAN, U.; MARTINI, M.; MARAN, T.; DOMEIER, M.; FURTNER, M. R. "The World is Upside Down": The Innsbruck Goggle Experiments of Theodor Erismann (1883-1961) and Ivo Kohler (1915-1985). Cortex, 92, p. 222-232, 2017.

SIMPSON, T. The Doctrine and Application of Fluxions: containing (besides what is common to the subject) a number of new improvements in the theory, and the solution of a variety of new and very interesting problems in different branches of mathematicks. London: Printed for John Nourse, 1776.

SMITH, A. M. From Sight to Light: The Passage from Ancient to Modern Optics. Chicago/London: University of Chicago Press, 2015.

SMITH, R. A Compleat System of Opticks. v. I. Cambridge: Printed for the author, 1738.

STEFFENS, H. The development of Newtonian optics in England. New York: Science History Publications/USA, 1977. 
WRIGHT, K. W. Anatomy and Physiology of Eye Movements. In: WRIGHT, K.W., SPIEGE P.H. (eds.) Pediatric Ophtalmology and Strabismus. New York: Springer, 2003.

YOUNG, T. Observations on the Appearances attending the Conversion of Cast into malleable iron. The Gentleman's Magazine, v. 21, p. 303-305, 1792.

YOUNG, T. Observations on Vision. Philosophical Transactions of the Royal Society, London, v. 83, p. 169-181, 1793.

YOUNG, T. The Bakerian Lecture: On the Mechanism of the Eye. Philosophical Transactions of the Royal Society, London, v. 91, p. 23-88, 1801.

YOUNG, T. A course of Lectures on Natural Philosophy and the Mechanical Arts. v. I. London: Printed for Joseph Johnson, 1807a.

YOUNG, T. A course of Lectures on Natural Philosophy and the Mechanical Arts. v. II. London: Printed for Joseph Johnson, 1807b.

YOUNG, T. Autobiographical Sketch. In: HILTS, V. L. Thomas Young's “Autobiographical Sketch". Proceedings of the American Philosophical Society, v. 122, n. 4, p. 248-260, 1978.

ZINN, J. G. Descriptio anatomica oculi humani iconibus illustrata. Gottingae: apud viduam B. Abrami Vadenhoeck, 1755. Disponível em: https://www.erara.ch/zuz/content/zoom/13184085. Acesso em: 10 out. 2021. 